\title{
Signs in radiology
}

\author{
IK Indrajit \\ Department of Radiodiagnosis and Imaging, INHS Asvini, Mumbai, India
}

Correspondence: Department of Radiodiagnosis and Imaging, INHS Asvini, Mumbai - 400 005, India. E-mail: inji63@gmail.com

Few useful websites and journal citations dealing with Signs in Radiology, that are available at the moment on the Internet, are mentioned and reviewed below:

1. Radiology, published by Radiological Society of North America (RSNA), is one of the "authoritative reference for the most current, clinically relevant, and highest quality research in the field of radiology". A trendy section Signs in Imaging is available at http://radiology.rsna.org/cgi/sectionsearch?tocsectio nid=Signs+ in+Imaging and displaysectionid=Signs + in+Imaging and journalcode=radiology and hits $=20$, wherein nearly 120 signs are illustratively discussed.

2. Radiology Signs is an illustrative section from Learning Radiology.com and is specifically available at http:// learningradiology.com/radsigns/radsignstoc.htm. The website LearningRadiology.com ${ }^{\mathrm{TM}}$ is designed and developed by William Herring, MD, FACR, at Einstein Medical Center in Philadelphia, Pennsylvania.

3. Signs in Imaging is an illustrative encyclopedia available online from Radiopedia at http://radiopaedia. org/encyclopaedia/signs/all. The signs can be browsed by several systems ranging from Breast, Cardiac, Central Nervous System, Chest to Gastrointestinal, Head and Neck, Obstetrics, Paediatrics, Urogenital and Vascular.

4. Classic Signs in Pediatric Radiology, is created by Michael P. D'Alessandro, MD, as a part of the peer reviewed web site Paediapaedia: An Imaging Encyclopedia of Pediatric Disease at http://www. virtualpediatrichospital.org/providers/PAP/ PAPHome.shtml. Specifically available at http://www. virtualpediatrichospital.org/providers/PAP/TOC/ Classics.shtml, the illustratively material focuses on the signs in neonatal chest.

5. Interactive Atlas of Signs in Musculoskeletal Radiology is a featured webpage created by A. Gentili, MD et al. from the UCSD, UCLA and WLA VAM. An

\begin{tabular}{|l|l|}
\hline \multicolumn{2}{|c|}{ Access this article online } \\
\hline Quick Response Code: & \\
\hline & Website: \\
\hline & www.ijri.org \\
\hline
\end{tabular}

alphabetic list of signs are on offer at http://www.gentili. net/signs/alphabeticlist.htm. These may alternatively be "reviewed by sign name, pathological diagnosis or locations" and are illustrated with radiographs and diagrams. Besides, "references are linked to PubMed, for immediate access to the abstract, if available".

6. Twenty Classic Signs in Neuroradiology: A pictorial essay by Govind B Chavhan and Manohar M Shroff, is featured in Indian Journal of Radiology and Imaging. The illustrative citation can be sourced from http:// www.ijri.org/article.asp?issn=0971-3026; year=2009; vol ume $=19$; issue $=2$; spage $=135$; epage $=145$; aulast=Chavhan . The material illustratively highlights the "appearance of signs, the reliability and sensitivity of the signs, and the differential diagnoses to be considered".

7. Signs in Chest Imaging is a citation published by Diagnostic and Interventional Radiology, Turkish Society of Radiology and is authored by Oktay Algin et al. from the Department of Radiology, Uludag University School of Medicine, Bursa, Turkey. It is available at http://www. dirjournal.org/text.php3?id $=324$. The material presents the topic with "most frequently encountered plain film and CT signs in chest imaging".

8. Radiologic Signs in Thoracic Imaging is a Case-Based Review and Self-Assessment Module written by Mark S. Parker et al. and published in American Journal of Roentgenology. Available at http://www.ajronline. org/doi/abs/10.2214/AJR.07.7081, the material helps in the "recognition and understanding of the radiologic signs that are characteristic of many complex disease processes", in few thoracic conditions.

9. Signs in Thoracic Imaging is authored by Geofrey B. Marshall, BSc, MD, et al. and published in Journal of Thoracic Imaging. Available from http://seicat.org/repo/ static/public/documentos/top10-toracica/Signs_in_ Thoracic_Imaging.pdf, the citation focuses on 23 classic roentgenographic signs used in thoracic imaging, that are recognizable, have characteristic patterns "that ultimately aid in the diagnosis and subsequent treatment of disease".

10. Selections from the Buffet of Food Signs in Radiology is authored by Roche CJ et al. from Department of Radiology, University College Hospital, Newcastle Rd, Galway, Ireland and published in Radiographics. The "food signs" material sourced from http://radiographics. rsna.org/content/22/6/1369.full, are "easily recognizable 
and include findings that resemble various fruits and vegetables allow confident diagnosis on the basis of imaging findings alone or narrowing of the differential diagnosis".

11. Classic Signs in Uroradiology is authored by Dyer $\mathrm{RB}$ et al. from Department of Radiology, Wake Forest University School of Medicine, Winston-Salem, NC and published in Radiographics. Available at http:// radiographics.rsna.org/content/24/suppl_1/S247.full, the material illustratively describes "classic signs accumulated from the literature to review a variety of pathologic conditions in the urinary tract".

\section{End Piece}

Signs in Musculoskeletal Radiology is "an open database of common and not so common signs used in Musculoskeletal Radiology" and available at http://www.
orthopaedicsone.com/display/Main/Signs+in+Musculosk eletal+Radiology.

Food Signs in Radiology is authored by Mehboob Hussain et al. in Int J Health Sci (Qassim) and available at http:// www.ncbi.nlm.nih.gov/pmc/articles/PMC3068652/. It illustratively features "classic radiological signs that resemble various types of food items like fruits, meat, vegetables, eggs, bakery, grocery and confectionary items". Classic Signs in Gastrointestinal Radiology is an illustrative three part feature published in Applied Radiology, that reviews "an array of classic signs associated with gastrointestinal tract pathologies whose imaging manifestations resemble everyday objects". All three are available on the net, commencing with the first part at http://www.appliedradiology.com/ Issues/2011/12/Articles/AR_12-11_Mortele_part 01/ Part-1--Classic-signs-in-gastrointestinal-radiology.aspx. 